\title{
Intraocular Invasion of Adult T-Cell Leukemia Cells without Systemic Symptoms after Cataract Surgery
}

\author{
Kazuichi Maruyama ${ }^{a}$, Kenji Nagata ${ }^{b}$ Kentaro Kojima $^{b}$ Toru Inaba $^{c}$ \\ Sunao Sugita $^{d}$ Manabu Mochizuki $^{\mathrm{e}}$ Shigeru Kinoshita ${ }^{\mathrm{b}}$ \\ ${ }^{a}$ Department of Ophthalmology and Visual Science, Tohoku University Graduate School of \\ Medicine, Sendai, Departments of ${ }^{b}$ Ophthalmology and ${ }^{C}$ Clinical Laboratory and Medicine, \\ Kyoto Prefectural University of Medicine, Kyoto, ${ }^{\mathrm{d}}$ RIKEN Center for Development Biology, \\ Kobe, and ${ }^{\mathrm{e}}$ Department of Ophthalmology, Tokyo Dental and Medical University, \\ Tokyo, Japan
}

\section{Key Words}

Adult T-cell leukemia $\cdot$ Intraocular invasion · Flow cytometry

\begin{abstract}
Adult T-cell leukemia (ATL) is an aggressive lymphoid proliferation associated with the human T-lymphotropic virus type I (HTLV-I). The intraocular invasion of ATL is a rare event. A 75-year-old man without any systemic disease underwent uneventful cataract surgery of the right eye. On postoperative day 6 , the patient presented with blurred vision due to severe vitreous opacity in the right eye. Analysis of the vitreous fluid revealed a suspected ATL infection based on the flow cytometric analysis. Moreover, cytological examination of the vitreous specimen revealed flower cell infiltration, and HTLV-1 DNA was detected by PCR analysis of the vitreous sample. Monoclonal T-cell receptor chain rearrangement was also detected by PCR. Thorough analysis of a vitreous sample is essential for vitrectomy in vitreous opacity of unknown cause. Flow cytometric, cytological, and PCR analysis of vitreous samples is beneficial for determining the cause of this kind of severe illness.
\end{abstract}

(c) 2013 S. Karger AG, Basel

\section{Introduction}

Adult T-cell leukemia (ATL) is an aggressive lymphoid proliferation associated with the human T-lymphotropic virus type I (HTLV-I) [1, 2]. HTLV-I causes transformation and clonal

Kazuichi Maruyama, MD, PhD

Department of Ophthalmology and Visual Science

Tohoku University Graduate School of Medicine

1-1 Seiryyo-cho Aoba-ku, Sendai 980-0872 (Japan)

E-Mail maruyama-k@oph.med.tohoku.ac.jp 
Maruyama et al.: Intraocular Invasion of Adult T-Cell Leukemia Cells without Systemic Symptoms after Cataract Surgery

expansion of T cells, resulting in ATL in approximately 1-4\% of the estimated 10-20 million infected hosts, with a mean latency period of $>50$ years. The diversity in clinical features and prognosis of patients with ATL has led to its subclassification into the following 4 subtypes: smoldering, chronic, acute leukemic forms, and ATL lymphoma [3]. Rare cases with intraocular invasion of acute-type ATL have been reported [4-6].

We reported previously that flow cytometric analysis of vitreous samples is useful for the diagnosis of ocular sarcoidosis [7]. Here, we report a patient with intraocular invasion of smoldering-type ATL after cataract surgery, which was confirmed by flow cytometric analysis, cytology, and PCR analysis of vitreous samples.

\section{Case Report}

This study was performed in accordance with the tenets of the Declaration of Helsinki, and the procedures were approved by the Institutional Review Board of the Kyoto Prefectural University of Medicine Hospital and Tohoku University Graduate School of Medicine. The patient gave informed consent for participation in this study.

A 75-year-old man without any systemic disease underwent uneventful cataract surgery of the right eye. The best-corrected visual acuity was 1.0 on the next day, with normal postoperative findings. On postoperative day 6 , the patient presented with blurred vision in the right eye without any specific clinical findings such as ocular pain. His best-corrected visual acuity had decreased to 0.5 , and funduscopic examination revealed diffuse vitreous opacity (fig. 1). Based on the clinical course and the ocular manifestations, postoperative bacterial endophthalmitis was suspected, and a pars plana vitrectomy was performed. A vitreous specimen was obtained at the start of a conventional 25-gauge pars plana vitrectomy. Dry vitrectomy without perfusion of a balanced salt solution (Alcon Laboratories, Inc., Fort Worth, Tex., USA) was conducted at a rate of 500 cuts per min so as not to damage cells infiltrating into the vitreous. After collecting $2 \mathrm{ml}$ of a pure vitreous sample, an additional vitrectomy was performed under balanced salt solution perfusion in order to collect $10 \mathrm{ml}$ of the diluted vitreous sample. Flow cytometric analysis of the diluted vitreous sample was performed [8]. Genomic DNA for herpes virus and other ocular pathogens was assayed in vitreous fluids using 2 independent PCR assays (a qualitative multiplex PCR assay and a quantitative real-time PCR assay) as described previously [9].

A high level of CD4 and CD8 double-positive T cells was detected in the vitreous fluid but not in the peripheral blood (fig. 2a, b), which is rarely seen in other cases of uveitis. Based on the result of flow cytometry, ATL or cytomegalovirus infection was suspected [10]. Cytological examination of the vitreous specimen revealed flower cells that infiltrated into the vitreous (fig. 2c). The proviral DNA for HTLV-I (but not for cytomegalovirus or other types of infectious organisms) was amplified in the pure vitreous sample. Quantitative PCR detected $8.80 \times 10^{4}$ copies $/ \mathrm{ml}$ in the pure vitreous sample. Monoclonal T-cell receptor chain rearrangement was also detected by PCR in the pure vitreous sample (fig. 2d). Based on these results, the patient was diagnosed with intraocular invasion of ATL.

The antibody against HTLV-I in serum was positive. The proviral DNA for the HTLV-I was amplified in the serum sample by PCR and was not found by Southern blot analysis. Just $1 \%$ of abnormal cells were detected in the peripheral blood. The rate of CD4 and CD8 double-positive $\mathrm{T}$ cells in the peripheral blood was low. No particular clinical findings were detected during an observation course of 12 months. Moreover, a PET scan revealed no abnormalities. 
Maruyama et al.: Intraocular Invasion of Adult T-Cell Leukemia Cells without Systemic Symptoms after Cataract Surgery

Based on these results, the patient was diagnosed with smoldering-type ATL. It was not necessary for this ATL patient to receive systemic treatment. After the vitrectomy, visual acuity in the right eye improved to 1.0. Fundus examination showed no recurrence for more than 12 months after surgery.

\section{Discussion}

As far as we are aware, this is the first report of a patient with intraocular invasion of smoldering-type ATL triggered by cataract surgery. Previously, a patient with smolderingtype ATL was reported with severe unilateral intraocular inflammation at the time of acute crisis during the disease process without any intraocular surgery [11]. In the present report, we speculate that the disruption of the blood-ocular barrier after cataract surgery triggered the intraocular infiltration of ATL cells in our patient with smoldering-type ATL. We surmise that the ATL cells might be affected by postoperative inflammation and a special ocular environment where a high amount of transforming growth factor beta (TGF- $\beta$ ) is found. It has been shown that ATL cells may proliferate under high concentrations of TGF- $\beta$ [12]. Based on this, in the present case we thought that infiltrating ATL cells gradually proliferated after the operation into the ocular fluid, where there was a high amount of TGF- $\beta$. In our patient, there was no recurrence even without additional treatment after vitrectomy.

Although this is a rare case, lymphocyte infiltrating disorder may be considered as a differential diagnosis in cases with diffuse vitreous opacity after intraocular surgery. Thorough analysis of vitreous samples is essential for vitrectomy in vitreous opacity from unknown causes. Flow cytometric, cytological, and PCR analysis of vitreous samples is beneficial for determining the cause of uveitis and endophthalmitis.

\section{Acknowledgement}

We would like to thank for Dr. Wendy Chao for editing and critical reading of the manuscript.

\section{Disclosure Statement}

Funding was received from KAKEN 10433244.

\section{References}

1 Uchiyama T, Yodoi J, Sagawa K, Takatsuki K, Uchino H: Adult T-cell leukemia: clinical and hematologic features of 16 cases. Blood 1977;50:481-492.

2 Bazarbachi A, Ghez D, Lepelletier Y, Nasr R, de Thé H, El-Sabban ME, Hermine O: New therapeutic approaches for adult T-cell leukaemia. Lancet Oncol 2004;5:664-672.

-3 Shimoyama M: Diagnostic criteria and classification of clinical subtypes of adult T-cell leukaemialymphoma. A report from the lymphoma study group (1984-1987). Br J Haematol 1991;79:428-437.

-4 Sugita S, Takase H, Yoshida T, Sugamoto Y, Watanabe T, Mochizuki M: Intraocular soluble IL-2 receptor alpha in a patient with adult T cell leukaemia with intraocular invasion. Br J Ophthalmol 2006;90:12041206.

5 Shibata K, Shimamoto Y, Nishimura T, Okinami S, Yamada H, Miyahara M: Ocular manifestations in adult Tcell leukemia/lymphoma. Ann Hematol 1997;74:163-168. 


\begin{tabular}{l|l}
\hline Case Rep Ophthalmol 2013;4:252-256 \\
\hline DOI: 10.1159/000355486 & $\begin{array}{l}\text { ○ 2013 S. Karger AG, Basel } \\
\text { www.karger.com/cop }\end{array}$ \\
\hline
\end{tabular}

Maruyama et al.: Intraocular Invasion of Adult T-Cell Leukemia Cells without Systemic Symptoms after Cataract Surgery

6 Hirata A, Miyazaki T, Tanihara H: Intraocular infiltration of adult T-cell leukemia. Am J Ophthalmol 2002;134:616-618.

-7 Kojima K, Maruyama K, Inaba T, Nagata K, Yasuhara T, Yoneda K, Sugita S, Mochizuki M, Kinoshita S: The CD4/CD8 ratio in vitreous fluid is of high diagnostic value in sarcoidosis. Ophthalmology 2012;119:23862392.

8 Nagata K, Maruyama K, Uno K, Shinomiya K, Yoneda K, Hamuro J, Sugita S, Yoshimura T, Sono da KH, Mochizuki M, Kinoshita S: Simultaneous analysis of multiple cytokines in the vitreous of patients with sarcoid uveitis. Invest Ophthalmol Vis Sci 2012:53:3827-3833.

$>9$ Miyanaga M, Sugita S, Shimizu N, Morio T, Miyata K, Maruyama K, Kinoshita S, Mochizuki M: A significant association of viral loads with corneal endothelial cell damage in cytomegalovirus anterior uveitis. $\mathrm{Br}$ ] Ophthalmol 2010;94:336-340.

10 Ohata J, Matsuoka M, Yamashita T, Tojo A, Tani K, Asano S: CD4/CD8 double-positive adult T cell leukemia with preceding cytomegaloviral gastroenterocolitis. Int J Hematol 1999;69:92-95.

-11 Kohno T, Uchida H, Inomata H, Fukushima S, Takeshita M, Kikuchi M: Ocular manifestations of adult T-cell leukemia/lymphoma. A clinicopathologic study. Ophthalmology 1993;100:1794-1799.

12 Arnulf B, Villemain A, Nicot C, Mordelet E, Charneau P, Kersual J, Zermati Y, Mauviel A, Bazarbachi A, Hermine 0: Human T-cell lymphotropic virus oncoprotein Tax represses TGF-beta 1 signaling in human $T$ cells via c-Jun activation: a potential mechanism of HTLV-I leukemogenesis. Blood 2002;100:4129-4138.
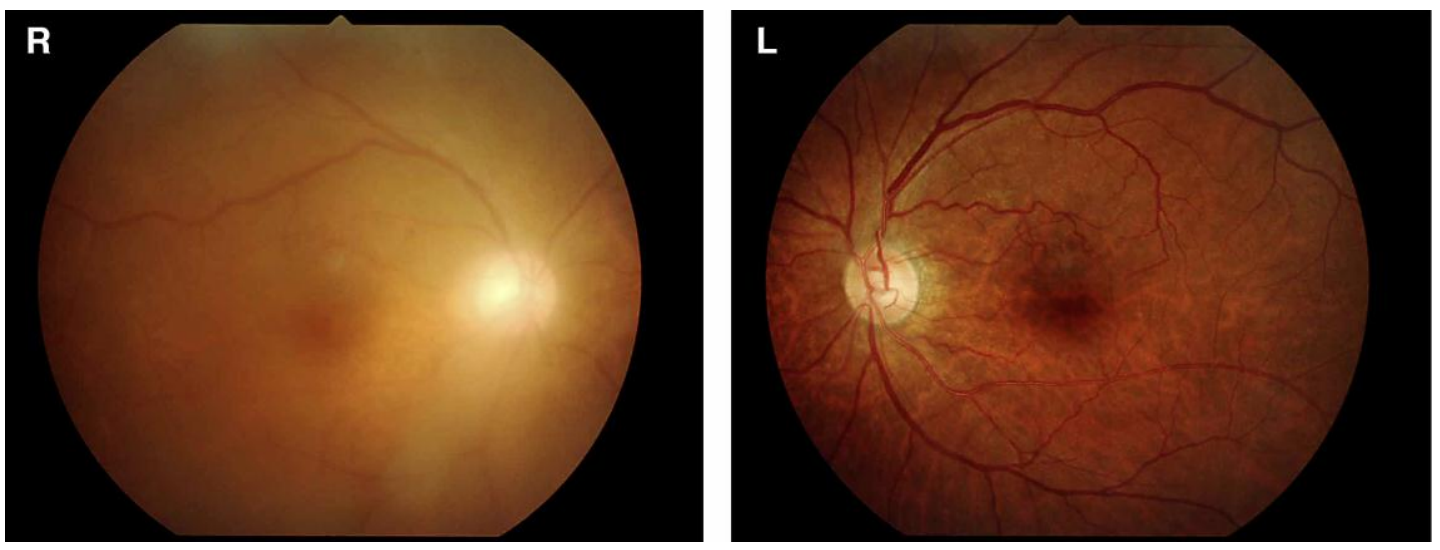

Fig. 1. Fundus findings before vitrectomy. A fundus photograph shows diffuse vitreous opacity in the right eye. The fundus became cloudy compared to the healthy eye. No obvious opacity can be seen in the left eye. 
Maruyama et al.: Intraocular Invasion of Adult T-Cell Leukemia Cells without Systemic Symptoms after Cataract Surgery

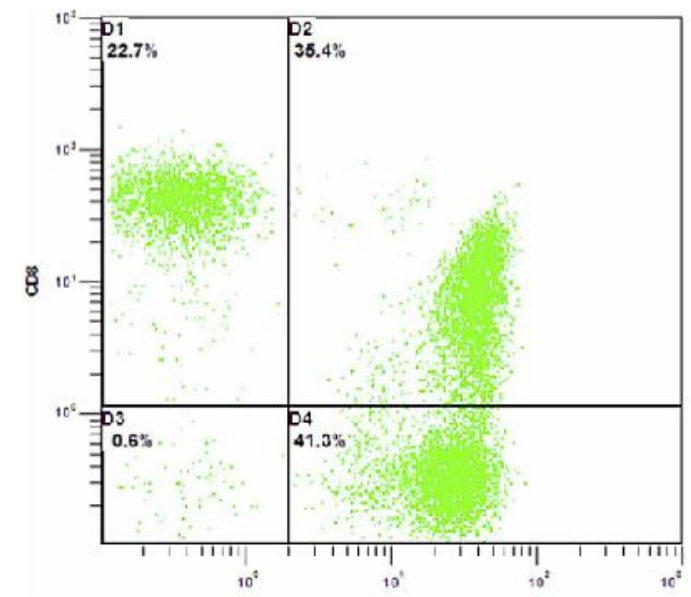

a

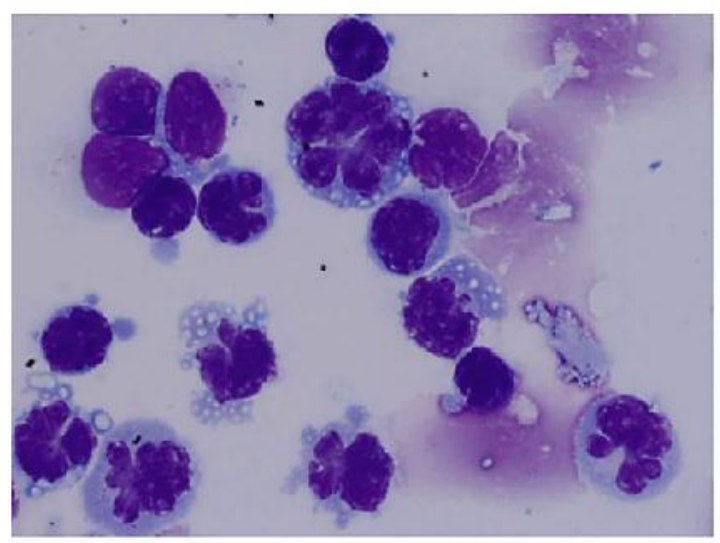

C
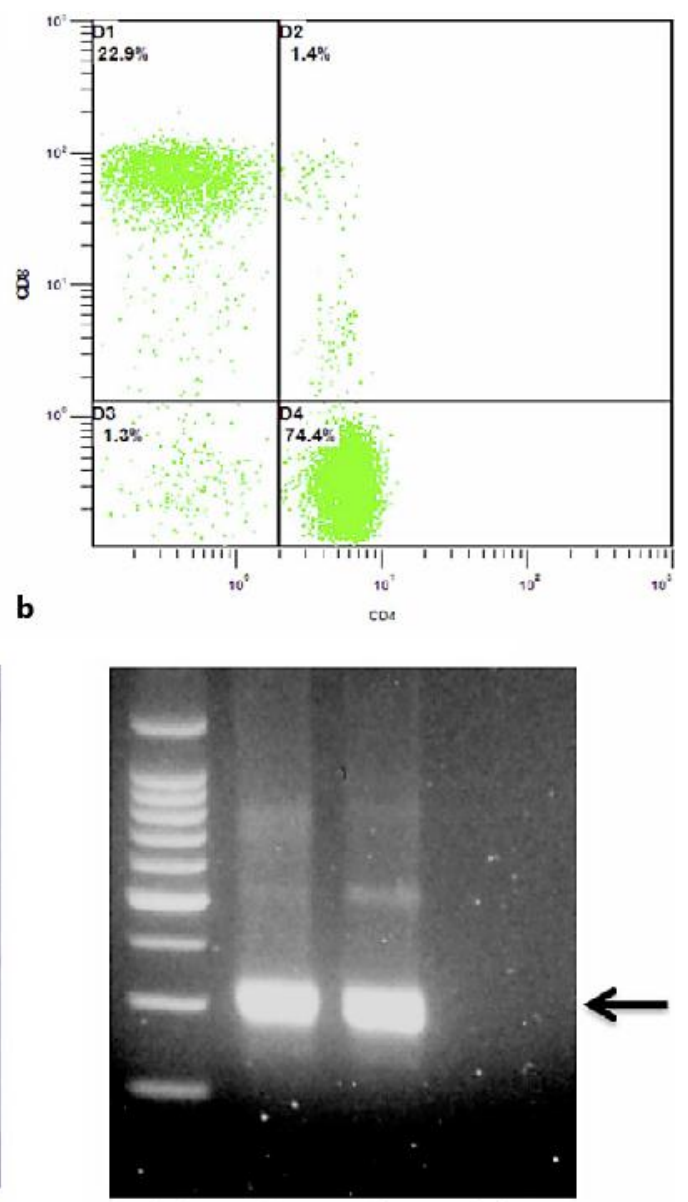

d $\begin{array}{llll}M & P & S & N\end{array}$

Fig. 2. Flow cytometry analysis reveals both the vitreous and the peripheral blood. a A high rate (35.4\%) of CD4 and CD8 double-positive T cells was detected in the vitreous sample. b A low rate (1.4\%) of CD4 and CD8 double-positive T cells was detected in the peripheral blood. c ATL flower cells can be seen in the vitreous sample. A large number of typical ATL cells were detected in the vitreous sample, which had many nuclear lobules and basophilic cytoplasm. $\mathbf{d}$ Detection of proviral DNA of HTLV-I in the vitreous of our ATL patient. $\mathrm{M}=$ Molecular size marker; $\mathrm{N}=$ negative control; $\mathrm{P}=$ positive control (HTLV-I-infected cells); $\mathrm{S}=$ vitreous sample of our ATL patient. Arrow indicates $300 \mathrm{bp}$. 